\title{
Effect of chronic administration of $7 \alpha$-methyl-19-nortestosterone on serum testosterone, number of spermatozoa and fertility in adult male bonnet monkeys (Macaca radiata)
}

\author{
S. G. Ramachandra ${ }^{1}$, V. Ramesh ${ }^{1}$, H. N. Krishnamurthy ${ }^{1}$, \\ N. Kumar ${ }^{2}$, K. Sundaram², M. P. Hardy ${ }^{3}$ and A. Jagannadha Rao ${ }^{3 *}$ \\ ${ }^{1}$ Primate Research Laboratory, Indian Institute of Science, Bangalore, India; ${ }^{2}$ Population \\ Council, Center for Biomedical Research, NY 10021, USA; and ${ }^{3}$ Department of Biochemistry \\ and Department of MRDG, Indian Institute of Science, Bangalore 560 012, India
}

\begin{abstract}
Hormonal approaches to male contraception that are based on the suppression of LH secretion require androgen replacement treatment to maintain sexual behaviour and secondary sexual characteristics. Androgen supplementation not only involves large and frequent doses of testosterone esters but also results in undesirable effects on the prostate gland. In an attempt to avoid such problems, a synthetic androgen, $7 \alpha$-methyl-19-nortestosterone (MENT), which is much more potent than testosterone, has been developed. In the present study, MENT was administered at different doses $\left(25,50,100,300\right.$ and $1000 \mu$ day $\left.^{-1}\right)$ either alone or in combination with oestradiol via Silastic implants for a specified period to adult male bonnet
\end{abstract}

monkeys (Macaca radiata). Blood and semen samples were collected at specific intervals and analysed for serum testosterone and seminal parameters, respectively. The results of the present study clearly indicate that administration of MENT at all doses tested results in suppression of the nocturnal surge of testosterone (by day 3 ), as well as a decrease in the number of spermatozoa (by day 45). Coadministration of oestradiol resulted in a reduction in the dose of MENT required to suppress the nocturnal surge. None of the male bonnet monkeys treated with MENT were able to impregnate females, clearly demonstrating the efficacy of MENT in blocking fertility in male bonnet monkeys.

\section{Introduction}

Sex steroids have been used to block the synthesis and secretion of pituitary gonadotrophins, thereby suppressing fertility in females. Although a similar approach using testosterone has shown some potential in males, a practical application that does not require frequent injections of androgen and incur the possible risk of over-stimulation of the prostate gland has yet to be developed. Long-acting testosterone derivatives, such as testosterone undecanoate, have been tested as potential male antifertility agents in an attempt to overcome this problem (Schurmeyer and Nieschlag, 1984; Weinbauer et al., 1986). In this regard, the synthetic androgen $7 \alpha$-methyl-19-nortestosterone (MENT) has been developed because of its high potency. The anabolic effects of MENT on skeletal muscle are ten times higher than those of testosterone (Sundaram et al., 1993). In the same study, it was also demonstrated that the potency of MENT as an androgen is four times higher than that of testosterone. However, unlike testosterone, MENT is not $5 \alpha$-reduced, so that the adverse stimulatory effects on the prostate gland are minimal (Agarwal and Monder, 1988; Kumar et al., 1992). In addition, MENT is also 12 times

*Correspondence

Email: ajrao@biochem.iisc.ernet.in more potent than testosterone in the suppression of serum gonadotrophin (Kumar et al., 1992). In the primate model, MENT is ten times more potent than testosterone with regard to the clinically desirable end points of gonadotrophin suppression and anabolism (Cummings et al., 1998). As oestradiol potently suppresses the hypothalamopituitary axis, augmentation of the antifertility potential of MENT was evaluated by testing the effects of chronic administration of MENT alone or in combination with oestradiol on the number of spermatozoa and fertility in adult male bonnet monkeys.

\section{Materials and Methods}

Animals

Colony-born adult male bonnet monkeys (Macaca radiata) of proven fertility (demonstrated by having sired at least one offspring) and female monkeys of proven fertility (that have given birth to at least one offspring) were selected for the study. Adult males, weighing $6-8 \mathrm{~kg}$, that showed a clear nocturnal surge of serum testosterone were included in this study. It was demonstrated previously that the serum testosterone concentration in samples collected at 22:00 h was at least threefold higher than that in samples collected at 10:00 h. The significance of the nocturnal surge of 
testosterone as an index of male reproductive function, and its dependence on $\mathrm{LH}$ and prolactin, has been reported by Rao et al. (1990). All the procedures carried out on the animals were approved by the Institutional Ethics Committee of the Indian Institute of Science (Protocol no. 21).

\section{Treatment}

Effect of MENT on the nocturnal surge of testosterone. MENT was obtained from the Center for Biomedical Research (New York). In the first set of experiments, MENT was delivered at a known rate for 28 days using an osmotic mini pump (model 2ML4; Alza Corporation, Palo Alto, CA) that was implanted s.c. and changed at intervals of 28 days. The doses of MENT administered were 100, 300 and $1000 \mu \mathrm{g}$ day $^{-1}$. The efficacy of MENT in suppressing the hypothalamo-pituitary-gonadal axis was assessed by its ability to inhibit the nocturnal surge of testosterone.

LH suppression. Five adult male monkeys were castrated bilaterally and 7 days later were implanted with miniosmotic pumps releasing $100 \mu \mathrm{g}$ MENT day ${ }^{-1}$ for 14 days to ascertain the ability of MENT to inhibit LH secretion. Blood samples were collected on day 7 and day 14 after implantation.

Effect of MENT alone or in combination with oestradiol on fertility. As fertility trials require a long period of treatment, dose responses for MENT were defined using Silastic implants, which provided a sustained release of the steroid. The preparation of Silastic capsules that were capable of delivering fixed concentrations of MENT was carried out according to the procedure described by Ewing et al. (1983). Accordingly, an appropriate length of Silastic tubing containing a fixed concentration of MENT was implanted to the back of each male monkey. Different doses of MENT were administered by varying the length of the Silastic implants as well as the number of implants. Silastic capsules delivering 25, 50, 100, 300 and $1000 \mu \mathrm{g} \mathrm{MENT} \mathrm{day}{ }^{-1}(n=5$ for each dose) were surgically implanted s.c. in the upper back region of each monkey.

\section{Surgery}

Animals were anaesthetized with ketamine hydrochloride (10 $\mathrm{mg} \mathrm{kg}^{-1}$ body weight). A small incision was made on the back of the monkey and Silastic implants containing MENT were placed in subcutaneous tissue and the wound was closed with silk sutures. The sutures were removed on day 7 after surgery.

Combination of MENT and oestradiol. A lower dose of MENT was tested in combination with oestradiol to explore the possibility of further enhancing the antigonadotrophic effect. A preliminary study revealed that a $1 \mathrm{~cm}$ Silastic capsule containing $11 \mathrm{mg}$ oestradiol is capable of maintaining serum oestradiol concentrations at $50 \mathrm{pg} \mathrm{ml}^{-1}$ for
150 days; oestradiol concentrations in control monkeys range between $5 \mathrm{pg} \mathrm{ml}^{-1}$ and $20 \mathrm{pg} \mathrm{ml}^{-1}$. On the basis of these results, Silastic capsules capable of delivering $25 \mu \mathrm{g}$ MENT and a capsule of oestradiol capable of maintaining serum oestradiol concentrations at $25 \mathrm{pg} \mathrm{ml}^{-1}$ were implanted in male bonnet monkeys. In another group of bonnet monkeys, the doses of both steroids were doubled.

The duration of the study ranged from 90 to 245 days. During this period, blood samples were collected on specified days at 10:00 $\mathrm{h}$ and 22:00 h, and serum was separated by centrifugation at $800 \mathrm{~g}$ for $20 \mathrm{~min}$ and stored at $-20^{\circ} \mathrm{C}$ until analysis. Semen samples were collected once every 15 days by penile stimulation (Ramesh et al., 1998), and the total number of spermatozoa and sperm motility were determined under a light microscopy. Sperm motility was scored on a scale ranging from highly motile $(+++++)$ to immotile (0).

Fertility trials. Fertility trials were conducted at specified time points between day 90 and day 180 with two groups of animals receiving hormone treatment via Silastic implants and the control group that received a placebo. The groups were as follows: (i) group 1: placebo (empty capsules) controls $(n=5)$; (ii) group 2: $100 \mu \mathrm{g}$ MENT alone each day $(n=5)$; (iii) group 3: $50 \mu \mathrm{g}$ MENT each day and a Silastic tube containing sufficient oestradiol to maintain serum oestradiol concentrations at $50 \mathrm{pg} \mathrm{ml}^{-1}$ throughout the experiment $(n=5)$. The fertility status of the animals was determined by keeping male bonnet monkeys in a cage with a female of proven fertility at days 9-14 of the menstrual cycle. The ovulatory status of the female was ascertained by determining serum oestradiol concentrations on days $7,8,9$ and 10 , and serum progesterone concentrations on days 18-24 of the menstrual cycle. In the primate colony at the Indian Institute of Science, the menstrual cycle is considered to be ovulatory when serum oestradiol concentrations are at least $200 \mathrm{pg} \mathrm{ml}^{-1}$ between day 7 and day 10 and serum progesterone values are at least $2 \mathrm{ng} \mathrm{ml}^{-1}$ between day 18 and day 24 of the menstrual cycle (Rao et al., 1997). Each male was kept in a cage with three different females during the fertile period of the menstrual cycle. This procedure was performed on the basis of data showing that a maximum of three exposures to a male of proven fertility for three ovulatory cycles is sufficient for a female to become pregnant (Rao et al., 1997). In addition, each female that did not become pregnant during the three exposures to a MENT-treated male was exposed again for three ovulatory cycles to a control male of proven fertility to ensure that the female monkey used in the study was fertile.

\section{Radioimmunoassay of hormones}

Serum LH concentrations were measured by radioimmunoassay using a macaque LH kit (generously provided by the NICHD, Bethesda, MD). The sensitivity of the radioimmunoassay was $0.1 \mathrm{ng} \mathrm{ml}^{-1}$, and the intra- and interassay coefficients of variation were 7.5 and $9.0 \%$, 


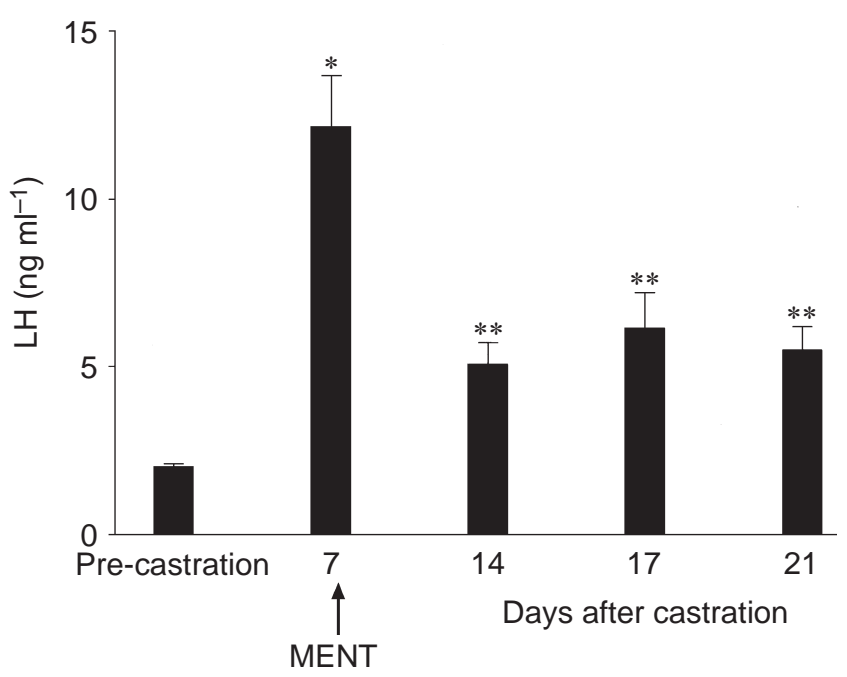

Fig. 1. Effect of administration of $7 \alpha$-methyl-19-nortestosterone (MENT) $\left(100 \mu \mathrm{g} \mathrm{day}^{-1}\right)$ on serum LH concentrations (mean \pm SEM, $n=5$ ) in male bonnet monkeys (Macaca radiata). Serum LH was estimated by radioimmunoassay using a macaque $\mathrm{LH}$ kit. *Significantly different from pre-castration value $(P<0.05)$, **Significantly different from day 7 value $(P<0.05)$.

respectively. Iodination of $\mathrm{LH}$ was carried out by the lodogen method (Salacinski et al., 1981). The specific activity of the ${ }^{125}$ I-labelled LH was $10-15 \mu \mathrm{ci} \mathrm{ng}^{-1}$. Serum testosterone concentrations were measured using a procedure described by Mukku et al. (1981). The assay had a sensitivity of $10 \mathrm{pg}$ per tube, and the intra- and interassay coefficients of variation were 8.3 and $9.8 \%$, respectively.

\section{Statistical analyses}

All data are expressed as mean \pm SEM. The hormonal concentrations and seminal parameters were analysed by ANOVA followed by Student-Newman-Keuls' comparisons to test for differences among means. Differences were regarded as significant at $P<0.05$.

\section{Results}

\section{Effect of administration of MENT on serum $\mathrm{LH}$ concentrations in castrated monkeys}

As expected, after castration, there was an increase in serum LH concentrations of male bonnet monkeys. However, an increase in serum LH concentration was not observed in castrated animals that were treated with $100 \mu \mathrm{g}$ MENT day ${ }^{-1}$ (Fig. 1) and this effect was observed even at day 14 after MENT treatment, indicating that administration of MENT results in inhibition of the hypothalamo-pituitarygonadal axis.

\section{Inhibition of the nocturnal surge of serum testosterone by MENT in intact monkeys}

Preliminary studies carried out using MENT delivered by the osmotic pumps showed that at all doses, suppression of the nocturnal surge of testosterone was observed by day 3 , and lower doses $(25$ and $50 \mu \mathrm{g})$ were as effective as higher doses $(P<0.005)$ (Table 1$)$. The profile of serum testosterone concentrations in the $100 \mu \mathrm{g}$ dose group is presented (Fig. 2); data from the other groups demonstrate the same outcome and are not shown. After removal of the MENT implants, the nocturnal testosterone surge reappeared within 10 days. Similar results were obtained when MENT was administered via Silastic capsules at doses of 25, 50, 100,300 and $1000 \mu \mathrm{g}$ per day.

\section{Suppression of spermatogenesis by MENT or MENT in combination with oestradiol}

Before the start of the experiment, the number of spermatozoa of the monkeys selected for the study ranged from $181 \times 10^{6}$ to $458 \times 10^{6}$ per ejaculate (Table 2). By day 45 , in addition to the abolition of the nocturnal surge of serum testosterone, a sharp decrease in the number of spermatozoa was observed, ranging from $9 \times 10^{6}$ to $87 \times 10^{6}$ per ejaculate (Table 2 ). A representative profile of the number of spermatozoa in monkeys that received $100 \mu \mathrm{g}$ MENT is presented (Fig. 3). At doses of 25-100 $\mu \mathrm{g}$ MENT, there was a trend towards steeper and more consistent decreases $(P<0.005)$ in the number of spermatozoa compared with the higher doses such as 300 and $1000 \mu \mathrm{g}$.

The data on serum testosterone concentrations are summarized (Figs 4 and 5) and indicate that, although both the MENT and oestradiol combination regimens were equally effective in suppressing the nocturnal serum testosterone surge, the suppression of the number of spermatozoa by treatment with $50 \mu \mathrm{g}$ MENT in combination with $50 \mathrm{pg}$ oestradiol was greater and more prolonged (Fig. 6) than the suppression after the $25 \mu \mathrm{g}$ MENT and 25 pg oestradiol regimen (Fig. 7). It should also be noted that although the number of spermatozoa remained suppressed in monkeys treated with $50 \mu \mathrm{g}$ MENT in combination with $50 \mathrm{pg}$ oestradiol, they tended to increase gradually in monkeys treated with $25 \mu \mathrm{g}$ MENT in combination with $25 \mathrm{pg}$ oestradiol $(P<0.005)$. Sperm motility was significantly reduced by day 45 after MENT administration (data not presented) and during the subsequent period there were too few spermatozoa to permit a reliable assessment of motility.

\section{Effect on fertility}

Of the several treatment regimens studied, only two groups of animals, that is, those receiving $100 \mu \mathrm{g}$ MENT or $50 \mu \mathrm{g}$ MENT + 50 pg oestradiol, were subjected to fertility testing because they showed the most consistent suppression of the number of spermatozoa.

The ovulatory nature of the menstrual cycle of the female monkeys exposed to the treated males is shown (Table 3). Only those cycles in which the values for serum oestradiol concentration on any day between day 7 and day 10 of the 
Table 1. Inhibition of the nocturnal surge of testosterone in intact bonnet monkeys (Macaca radiata) treated with $7 \alpha$-methyl-19-nortestosterone (MENT)

\begin{tabular}{lccrr}
\hline & \multicolumn{3}{c}{ Serum testosterone $\left(\mathrm{ng} \mathrm{m}^{-1}\right)$} \\
\cline { 2 - 5 } & \multicolumn{2}{c}{ Day 0 } & \multicolumn{2}{c}{ Day 3 } \\
\cline { 2 - 5 } Group & $10: 00 \mathrm{~h}$ & $22: 00 \mathrm{~h}$ & $10: 00 \mathrm{~h}$ & $22: 00 \mathrm{~h}$ \\
\hline Control & $2.63 \pm 0.73$ & $19.40 \pm 3.82$ & $3.98 \pm 0.70$ & $23.20 \pm 4.55$ \\
MENT $(\mu \mathrm{g})$ & & & \\
25 & $5.08 \pm 0.46$ & $15.83 \pm 2.89$ & $2.20 \pm 0.40$ & $1.58 \pm 0.21$ \\
50 & $4.70 \pm 0.76$ & $20.80 \pm 5.40$ & $2.33 \pm 0.19$ & $1.33 \pm 0.29$ \\
100 & $3.40 \pm 1.40$ & $13.10 \pm 2.20$ & $2.52 \pm 0.25$ & $2.24 \pm 0.44$ \\
300 & $4.42 \pm 1.82$ & $12.80 \pm 3.16$ & $2.99 \pm 0.45$ & $3.20 \pm 0.40$ \\
1000 & $4.25 \pm 1.10$ & $15.10 \pm 3.30$ & $4.50 \pm 0.75$ & $3.93 \pm 0.51$ \\
\hline
\end{tabular}

Values are mean $\pm \mathrm{SE}(n=5$ animals $)$.

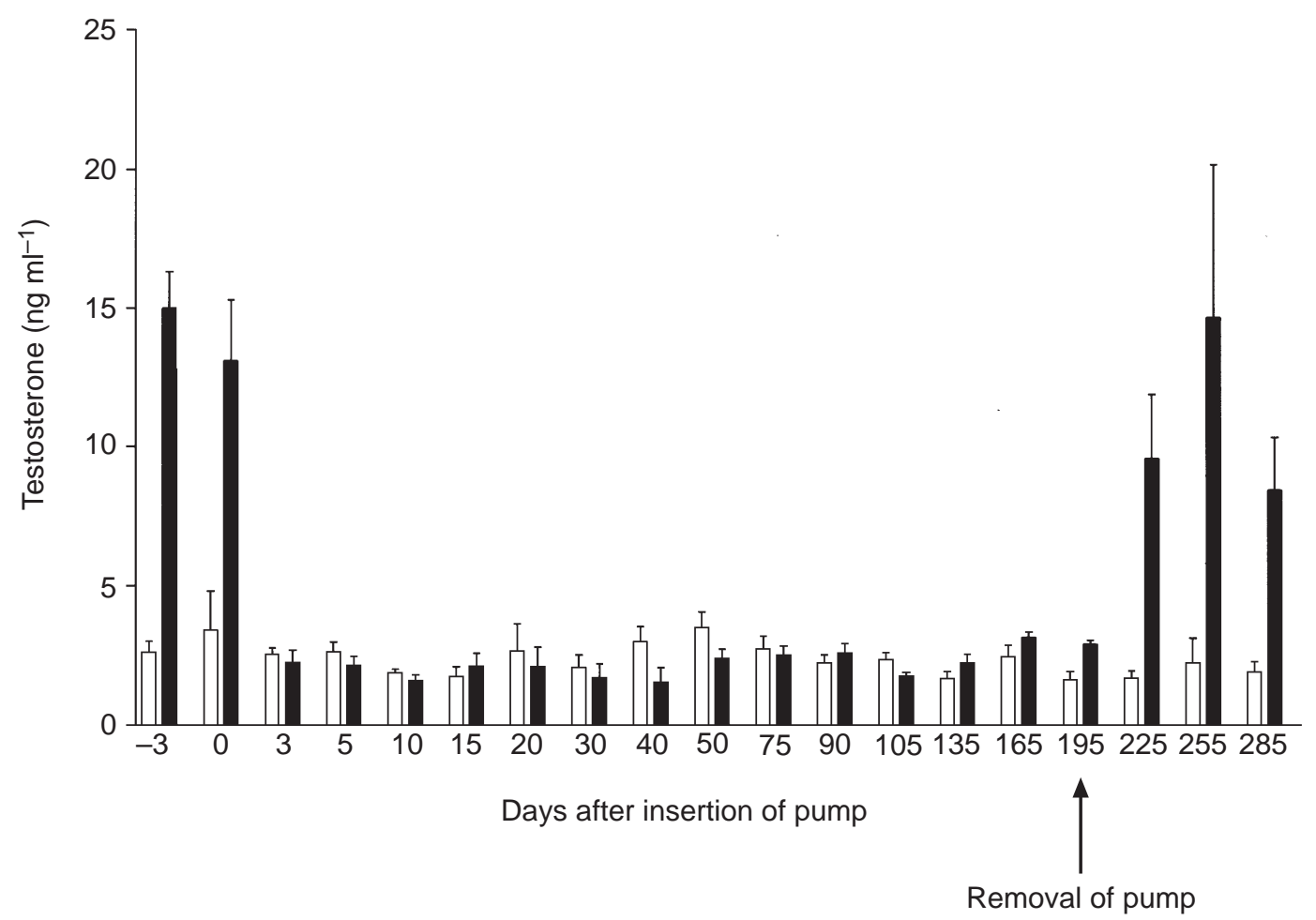

Fig. 2. Effect of administration of $7 \alpha$-methyl-19-nortestosterone (MENT) (100 $\mu$ g day $\left.{ }^{-1}\right)$ via Silastic tubing on serum testosterone concentrations in serum samples collected at 10:00 $\mathrm{h}(\square)$ and at 22:00 $\mathrm{h} \mathrm{( \square )} \mathrm{from} \mathrm{male}$ bonnet monkeys (Macaca radiata). Serum testosterone was estimated by radioimmunoassay and values presented are mean \pm SE of five animals.

menstrual cycle were $200 \mathrm{pg} \mathrm{ml}^{-1}$ or above and serum progesterone concentration on any day between 18 and 24 was above $2 \mathrm{ng} \mathrm{ml}^{-1}$ were considered ovulatory and only such cycles were included in calculating the results.

The results from the present study reveal that although all the female monkeys exposed to untreated control males became pregnant, none of the females exposed to MENT or MENT + oestradiol-treated males became pregnant (Table 4). A total of ten females was exposed during three ovulatory cycles each (total of 30 cycles) to males in the
$100 \mu \mathrm{g}$ MENT-treated group. The males that received $50 \mu \mathrm{g}$ MENT in combination with $50 \mathrm{pg}$ oestradiol were exposed to five females during three ovulatory cycles for a total of 15 cycles. Interestingly, the females that were not impregnated by the MENT-treated males became pregnant within three exposures to control male monkeys, thus demonstrating that the females used were of normal fertility, and that the absence of pregnancy after exposure to MENT-treated males was not due to non-ovulatory cycles occurring at the time of the experiment. These results indicate that in 
Table 2. Inhibition of the nocturnal surge of testosterone and sperm count in bonnet monkeys (Macaca radiata) treated with $7 \alpha-$ methyl-19nortestosterone (MENT)

\begin{tabular}{|c|c|c|c|c|c|c|}
\hline \multirow[b]{3}{*}{ Group } & \multirow{2}{*}{\multicolumn{2}{|c|}{$\begin{array}{c}\text { Sperm count } \\
\left(10^{6} \text { per ejaculate }\right)\end{array}$}} & \multicolumn{4}{|c|}{ Serum testosterone $\left(\mathrm{ng} \mathrm{ml}^{-1}\right)$} \\
\hline & & & \multicolumn{2}{|c|}{ Day 0} & \multicolumn{2}{|c|}{ Day 45} \\
\hline & Day 0 & Day 45 & $10: 00 \mathrm{~h}$ & $22: 00 \mathrm{~h}$ & $10: 00 \mathrm{~h}$ & $22: 00 \mathrm{~h}$ \\
\hline $\begin{array}{l}\text { Control } \\
\text { MENT }(\mu \mathrm{g})\end{array}$ & $285 \pm 34$ & $258 \pm 17$ & $2.63 \pm 0.73$ & $19.40 \pm 3.82$ & $4.25 \pm 0.48$ & $17.40 \pm 2.29$ \\
\hline 25 & $181 \pm 6$ & $9 \pm 8$ & $5.08 \pm 0.46$ & $15.83 \pm 2.89$ & $1.85 \pm 0.44$ & $0.78 \pm 0.56$ \\
\hline 50 & $246 \pm 63$ & $21 \pm 9$ & $4.70 \pm 0.76$ & $20.80 \pm 5.40$ & $2.10 \pm 0.76$ & $0.78 \pm 0.26$ \\
\hline 100 & $224 \pm 20$ & $43 \pm 9$ & $3.40 \pm 1.40$ & $13.10 \pm 2.20$ & $3.01 \pm 0.53$ & $1.54 \pm 0.54$ \\
\hline 300 & $458 \pm 32$ & $85 \pm 26$ & $4.42 \pm 1.82$ & $12.80 \pm 3.16$ & $3.05 \pm 0.16$ & $2.53 \pm 0.33$ \\
\hline 1000 & $300 \pm 43$ & $87 \pm 20$ & $4.25 \pm 1.10$ & $15.10 \pm 3.30$ & $2.18 \pm 0.97$ & $1.27 \pm 0.67$ \\
\hline
\end{tabular}

Values are mean $\pm \operatorname{SE}(n=5$ animals $)$.

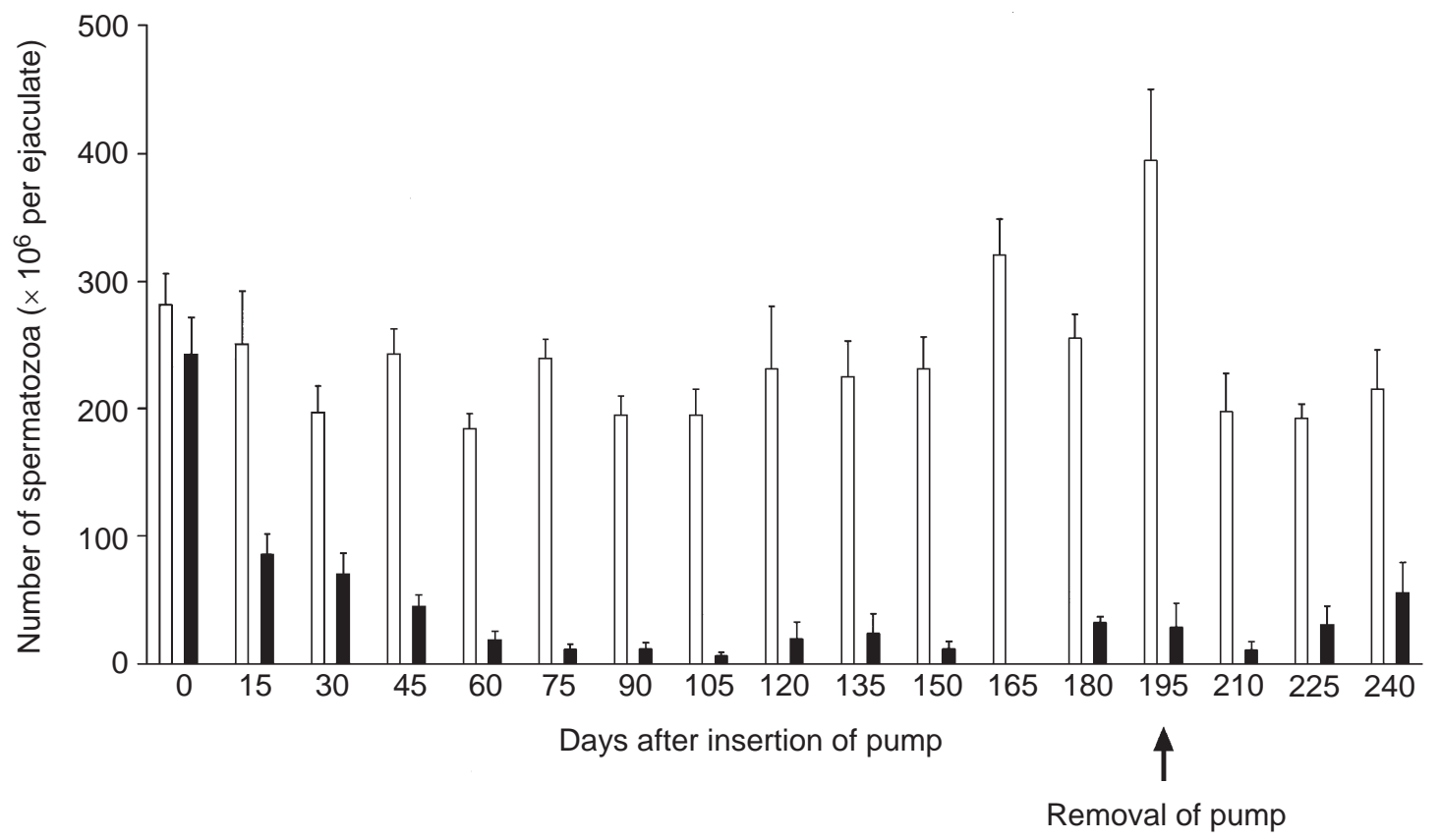

Fig. 3. Effect of administration of $100 \mu \mathrm{g} 7 \alpha$-methyl-19-nortestosterone (MENT) on the number of spermatozoa in adult male bonnet monkeys (Macaca radiata). Each value represents mean \pm SE of five monkeys. $\square$ : Control; $100 \mu \mathrm{g}$ MENT.

these monkeys, suppression of the hypothalamo-pituitarygonadal axis with an optimal dose of MENT alone or in combination with oestradiol at appropriate doses leads to infertility.

\section{Discussion}

The results of the present study clearly establish that administration of MENT causes a pronounced decline in the nocturnal surge of serum testosterone as early as day 3 after treatment and a significant decrease in the total number of spermatozoa at all doses of MENT tested. Although the concept of using feedback inhibition of hypothalamopituitary-gonadal axis by testosterone in males was tested by Reddy and Rao (1972), there has been comparatively little progress in practical application of this idea since the feasibility study published by a consortium backed by the World Health Organization (Anonymous, 1990). The lack of further study has been mainly attributable to the large dose of testosterone required to enforce azoospermia or, in the case of a GnRH antagonist, the necessity of androgen supplementation to maintain libido. Over the years, several long-acting derivatives of testosterone, such as enanthate and busiclate, have been used to supplement and suppress spermatogenesis in the limited clinical trials.

As several of the hormonal approaches to male contraception involved androgen supplementation, there have been attempts to synthesize potent androgen derivatives. 


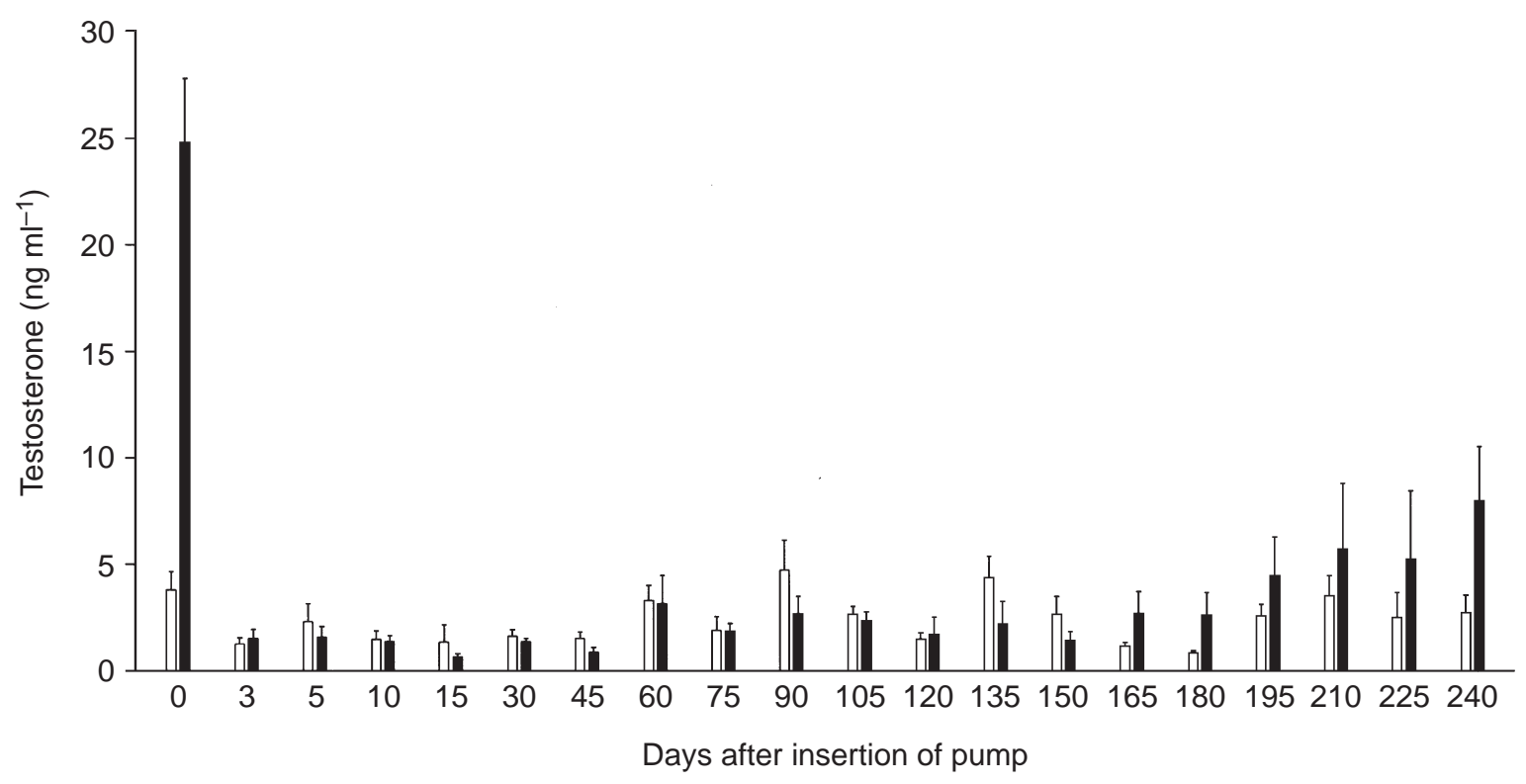

Fig. 4. Effect of administration of $50 \mu \mathrm{g} 7 \alpha$-methyl-19-nortestosterone MENT and 50 pg oestradiol on serum testosterone concentrations in adult male bonnet monkeys (Macaca radiata). Each value represents mean \pm SE of five monkeys. Samples were collected at 10:00 h ( $\square)$ and at 22:00 $\mathrm{h}(\mathbf{\square})$.

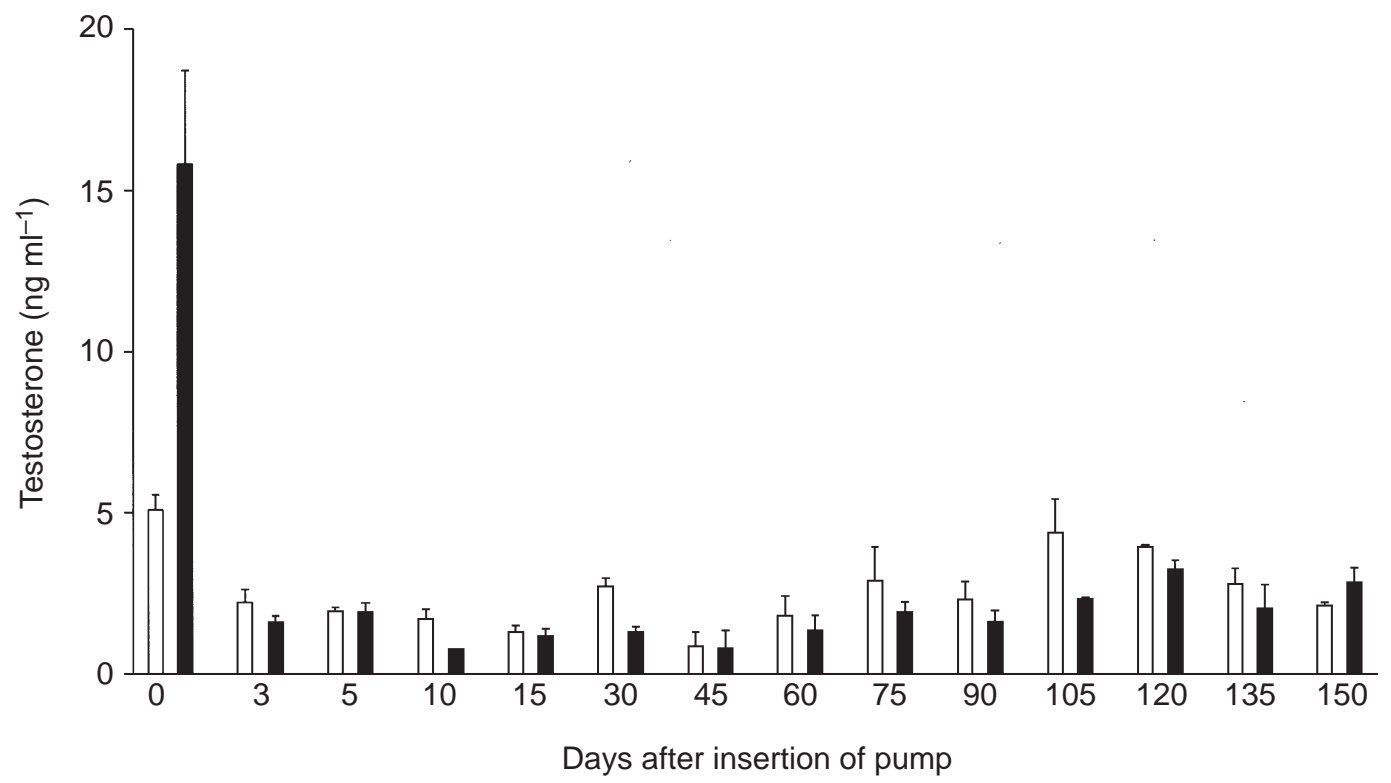

Fig. 5. Effect of administration of $25 \mu \mathrm{g} 7 \alpha$-methyl-19-nortestosterone (MENT) and 25 pg oestradiol on serum testosterone concentrations in adult male bonnet monkeys (Macaca radiata). Each value represents mean \pm SE of five monkeys. Samples were collected at 10:00 h ( $\square)$ and at 22:00 h (口).

One such compound, MENT, has been evaluated extensively for its androgenic potency (Sundaram et al., 1996). It has been demonstrated that MENT can be administered as a substitute for testosterone for 1 year by sub-dermal implants. MENT does not undergo $5 \alpha$-reduction and is ten times more potent than testosterone in suppressing the increase in the gonadotrophin concentrations after castration. In Macaca fascicularis, administration of $100 \mu \mathrm{g}$
MENT per day maintained prostate volume (Cummings et al., 1998). This finding indicates that doses of this steroid that result in gonadotrophic suppression neither hyperstimulate the prostate gland nor detract from its normal secretory function.

After establishing a minimum dose of MENT for effective suppression of the nocturnal surge of testosterone, we considered whether further inhibition of the reproductive 


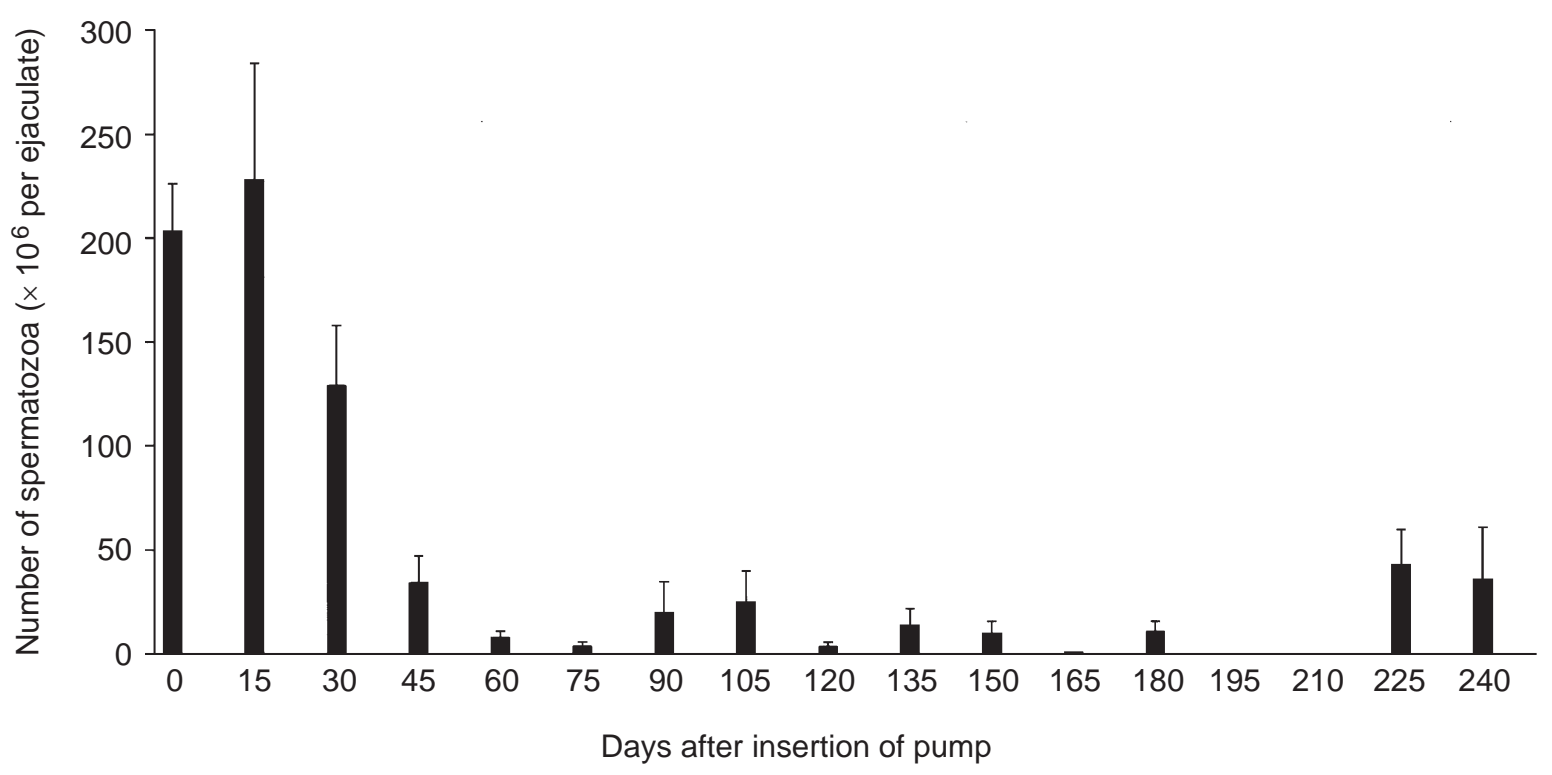

Fig. 6. Effect of administration of $50 \mu \mathrm{g} 7 \alpha$-methyl-19-nortestosterone (MENT) plus 50 pg oestradiol on the number of spermatozoa in adult male bonnet monkeys (Macaca radiata). Each value represents mean \pm SE of five monkeys.

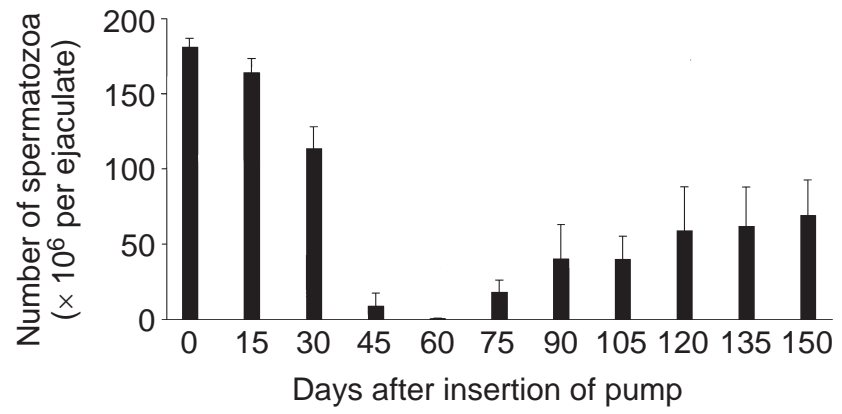

Fig. 7. Effect of administration of $25 \mu \mathrm{g} \quad 7 \alpha$-methyl-19nortestosterone (MENT) plus $25 \mathrm{pg}$ oestradiol on the number of spermatozoa in adult male bonnet monkeys (Macaca radiata). Each value represents mean \pm SE of five monkeys.

axis could be achieved by adding a low dose of oestrogen, because oestradiol is the most potent suppressor of $\mathrm{LH}$ secretion among the sex steroids (Ewing et al., 1983). Moreover, a recent study in humans showed that administration of oestradiol in combination with testosterone by sub-dermal depot release augmented the gonadotrophic suppression compared with testosterone alone (Handelsman et al., 2000). Although the study on humans did not record a change in the final percentage of men that achieved azoospermia with oestrogen supplementation, this issue remains open for exploration using a greater range of dosage combinations and with MENT as the androgen. Thus, it is hypothesized that because the aromatized metabolite of MENT is more oestrogenic than oestradiol, the aromatized metabolite of testosterone, a MENT + oestradiol combination would effectively suppress male fertility.
In the present study, the effects of administering MENT alone or in combination with oestradiol were evaluated in adult male bonnet monkeys. This species of monkey has been used extensively for a variety of studies and all the reproductive hormone profiles have been published (Rao et al., 1997). The bonnet monkey breeds well in captivity and under controlled breeding (that is, using animals that show ovulatory cycles, with a fertility index of $80-85 \%$; Rao et al., 1997). The results of the present study clearly establish that administration of MENT results in suppression of the nocturnal surge of testosterone as well as a decrease in the number of spermatozoa. In addition, the combined dose regimens of MENT + oestradiol were more effective than MENT alone in suppressing the nocturnal surge of serum testosterone and decreasing the number of spermatozoa. Of the two combination doses tested, $50 \mu \mathrm{g}$ MENT with $50 \mathrm{pg}$ oestradiol was more effective than $25 \mu \mathrm{g}$ MENT $+25 \mathrm{pg}$ oestradiol at suppressing both parameters.

Administration of MENT was associated with a decrease in testosterone concentrations observed as early as day 3 of treatment, but the decrease in the number of spermatozoa was observed only after day 45 . It was evident that these effects were specific to MENT as both testosterone concentrations and the number of spermatozoa returned to normal within a short period after removal of the implants. The ability of MENT to interfere with hypothalamo-pituitarygonadal axis was also evident from the decrease in the after castration increase in serum LH concentrations.

The ability of lower doses of MENT to suppress serum testosterone concentrations and the number of spermatozoa more effectively than the higher doses of MENT (300 and $1000 \mu \mathrm{g}$ ) could be due to the inherent androgenic effects at the higher doses. This is also evident from the fact that none 
Table 3. Serum concentration of oestradiol and progesterone in female bonnet monkeys (Macaca radiata) used for breeding studies with male monkeys that were treated with $7 \alpha$-methyl-19nortestosterone (MENT)

\begin{tabular}{lcccc}
\hline Group & $\begin{array}{c}\text { Total } \\
\text { number of } \\
\text { animals }\end{array}$ & $\begin{array}{c}\text { Total number of } \\
\text { ovulatory cycles } \\
\text { exposed }\end{array}$ & $\begin{array}{c}\text { Peak serum } \\
\text { oestradiol }^{\mathrm{a}} \\
\left(\mathrm{pg} \mathrm{m}^{-1}\right)(\text { days } 7-10)\end{array}$ & $\begin{array}{c}\text { Peak serum } \\
\text { progesterone }^{\mathrm{a}}\end{array}$ \\
\hline $\begin{array}{c}\left.\mathrm{ng} \mathrm{m}^{-1}\right)(\text { days 16-24) } \\
\text { Control }\end{array}$ & 5 & 20 & $429.13 \pm 20.25$ & $4.18 \pm 0.16$ \\
$\begin{array}{l}100 \mu \mathrm{g} \text { MENT }(n=10) \\
50 \mu \mathrm{gENT}+50 \mathrm{pg}\end{array}$ & 10 & 30 & $535.80 \pm 40.36$ & $2.82 \pm 0.13$ \\
oestradiol $(n=5)$ & 5 & 15 & $680.00 \pm 38.35$ & $2.93 \pm 0.12$ \\
\hline
\end{tabular}

aMaximum concentration of serum oestradiol on any day between day 7 and day 10 and maximum concentration of serum progesterone on any day between day 16 and day 24 was considered for calculation.

Values are mean $\pm \mathrm{SE}$.

Table 4. Fertility study on $7 \alpha$-methyl-19-nortestosterone (MENT)-treated and control bonnet monkeys (Macaca radiata)

\begin{tabular}{lccc}
\hline Group & Number of animals & $\begin{array}{c}\text { Number of ovulatory } \\
\text { cycles exposed }\end{array}$ & Number of pregnancies \\
\hline Control & 5 & 20 & 15 \\
$100 \mu \mathrm{g}$ MENT & 10 & 30 & 0 \\
$50 \mu \mathrm{g}$ MENT +50 pg oestradiol & 5 & 15 & 0 \\
\hline
\end{tabular}

of the animals treated with MENT showed muscle wasting, loss of body weight or testicular volume, which are commonly seen when testosterone concentrations are decreased. In fact, all of the animals gained weight during the course of the treatment period, which provides additional evidence of the anabolic effect of MENT. It has been reported previously that a combination of testosterone and oestradiol is more effective in inhibiting $\mathrm{LH}$ release, testicular testosterone production and thus spermatogenesis compared with testosterone alone (Ewing et al., 1983). It was therefore of interest to examine whether the inclusion of oestradiol in combination with MENT was more effective than MENT alone. The results from the present study indicate that inclusion of $50 \mathrm{pg}$ oestradiol in combination with $50 \mu \mathrm{g}$ MENT was more effective than $100 \mu \mathrm{g}$ MENT alone. This dose of oestradiol did not cause detectable gynaecomastia as judged by physical examination of the animals. These results indicate that MENT in combination with oestradiol may be potentially exploited for male contraception and at the same time avoids the unwanted side effects of increased oestrogen action. Further refinement of this potential may be realized with the advent of selective oestrogen response modulators (Thiebaud and Secrest, 2001). It may be possible, for example, to develop a MENT + oestradiol regimen using a selective oestrogen response modulator in place of oestradiol, thereby potentiating the antigonadotrophic effects of the synthetic androgen without changing, or even decreasing, the circulating concentrations of oestradiol.

Fertility studies have clearly established the efficacy of MENT in interfering with fertility in the treated monkeys.
None of the 15 monkeys treated with MENT was able to impregnate females of proven fertility, and these females did become pregnant when exposed to control males, thus establishing that the females used for breeding studies were of normal fertility. It is pertinent to note that in a clinical study (Noe et al., 1999), it has been demonstrated that administration of MENT by implants resulted in a dosedependent decrease in gonadotrophin and serum androgen concentrations, without adverse reactions or changes in clinical chemistry and haematology.

Taken together, the results of the present study indicate that a low dose of MENT is effective in suppressing gonadotrophins with consequent antifertility effects, without resulting in adverse effects on libido or weight loss. The effective dose of MENT may be lowered further by combined administration of low-dose oestradiol.

Financial support for maintenance of the Primate Research Laboratory from the Indian Institute of Science and Department of Biotechnology, Government of India, is gratefully acknowledged. The authors wish to thank the Mellon Foundation, the Population Council and CONRAD for funding these studies. The authors also would like to thank the Indian Council of Medical Research by way of an Advanced Centre for Cellular and Molecular Reproduction. Finally, the authors deeply appreciate the overview and administrative guidance provided by D. Colvard.

\section{References}

Agarwal AK and Monder C (1988) In vitro metabolism of $7 \alpha$-methyl-19nortestosterone by rat liver, prostate and epididymis: comparison with testosterone and 19-nortestosterone Endocrinology 123 2187-2193 
Anonymous (1990) Contraceptive efficacy of testosterone-induced azoospermia in normal men. World Health Organization Task Force on methods for the regulation of male fertility Lancet 336 (8721) 955-959

Cummings DE, Kumar N, Bardin W, Sundaram K and Bremner WJ (1998) Prostate-sparing effects in primates of the potent androgen $7 \alpha$-methyl19-nortestosterone: a potential alternative to testosterone for androgen replacement and male contraception Journal of Clinical Endocrinology and Metabolism 83 4212-4219

Ewing LL, Cochran RC, Adams RJ, Darney KJ, Jr, Berry SJ, Bordy MJ and Desjardins C (1983) Testicular function in rhesus monkeys treated with a contraceptive formulation Contraception 27 347-361

Handelsman DJ, Wishart S and Conway AJ (2000) Oestradiol enhances testosterone-induced suppression of human spermatogenesis Human Reproduction 15 672-679

Kumar N, Didolkar AK, Monder C, Bardin CW and Sundaram K (1992) The biological activity of $7 \alpha$-methyl-19-nortestosterone is not amplified in the male reproductive tract as is that of testosterone Endocrinology $\mathbf{1 3 0}$ 3677-3683

Mukku VR, Murthy GSRC, Srinath BR, Ramasharma K, Kotagi SG and Moudgal NR (1981) Regulation of testosterone rhythmicity by gonadotropins in bonnet monkeys (Macaca radiata). Biology of Reproduction $24814-819$

Noe G, Suvisaari J, Martin C, Moo-Young AJ, Sundaram K, Saleh SI, Quintero E, Croxatto HB and Lahteenmaki P (1999) Gonadotropin and testosterone suppression by $7 \alpha$-methyl-19-nortestosterone acetate administered by sub-dermal implant to healthy men Human Reproduction 14 2200-2206

Ramesh V, Ramachandra SG, Krishnamurthy HN and Rao AJ (1998) Electroejaculation and seminal parameters in bonnet monkeys (Macaca radiata). Andrologia 30 97-100

Rao AJ, Sheela Raini CS, Ravindranath N and Moudgal NR (1990) Effect of modulating endogenous prolactin secretion on testosterone production in the adult male bonnet monkey (Macaca radiata). Andrologia 22 251-259
Rao AJ, Ramesh V, Ramachandra SG, Krishnamurthy HN, Ravindranath N and Moudgal NR (1997) Breeding of bonnet monkeys (Macaca radiata) in captivity Laboratory Animal Science 47 180-183

Reddy PRK and Rao JM (1972) Reversible antifertility action of testosterone propionate in human males Contraception 5 295-301

Salacinski PR, McLean C, Sykes JE, Clement-Jones VV and Lowry PJ (1981) lodination of proteins, glycoproteins and peptides using a solid-phase oxidizing agent, 1,3,4,6-tetrachloro-3 alpha, 6 alpha-diphenyl glycoluril (lodogen) Annals of Biochemistry 117 136-146

Schurmeyer T and Nieschlag E (1984) Comparative pharmacokinetics of testosterone enanthate and testosterone cyclohexane carboxylate as assessed by serum and saliva testosterone in normal men International Journal of Andrology 7 181-187

Sundaram K, Kumar N and Bardin CW (1993) 7 $\alpha$-Methyl-19-nortestosterone (MENT); the optimal androgen for male contraception Annals of Medicine 25 199-205

Sundaram K, Kumar N and Bardin CW (1996) 7 $\alpha$-Methyl-19-nortestosterone (MENT): an ideal androgen for replacement therapy. In Pharmacology, Biology and Clinical Application of Androgens pp 493-497. Wiley-Liss Inc., New York

Thiebaud D and Secrest RJ (2001) Selective estrogen receptor modulators: mechanism of action and clinical experience. Focus on raloxifene Reproduction, Fertility and Development $13331-336$

Weinbauer GF, Marshall GR and Nieschlag E (1986) New injectable testosterone ester maintains serum testosterone of castrated monkeys in normal range for four months Acta Endocrinologia 113 128-132

Received 11 December 2001.

First decision 11 January 2002.

Revised manuscript received 2 April 2002.

Accepted 18 April 2002. 